\title{
PADRÕES COMPORTAMENTAIS DE BOVINOS CONFINADOS COM GRÃOS DE MILHO, AVEIA BRANCA OU ARROZ COM CASCA
}

\section{BEHAVIORAL PATTERNS OF FEEDLOT BOVINES FED WITH CORN GRAIN, WHITE OAT OR RICE WITH HULL}

\author{
Flânia Mônego Argenta ${ }^{1^{*}}$ - ORCID - http://orcid.org/0000-0002-0150-6607 \\ Jonatas Cattelam² - ORCID - https://orcid.org/0000-0002-4395-2189 \\ Dari Celestino Alves Filho ${ }^{3}$ - ORCID - http://orcid.org/0000-0003-2559-7504 \\ Ivan Luiz Brondani ${ }^{3}$ - ORCID - http://orcid.org/0000-0002-6526-3042 \\ Paulo Santana Pacheco3 - ORCID - https://orcid.org/0000-0003-1432-2599 \\ Ana Paula Machado Martini ${ }^{4}$ - ORCID - http://orcid.org/0000-0002-1963-9424 \\ ${ }^{1}$ Instituto Federal de Educação, Ciência e Tecnologia do Rio Grande do Sul, Vacaria, RS, Brasil. \\ 2 Universidade Federal Fronteira Sul, Realeza, PR, Brasil. \\ 3Universidade Federal de Santa Maria, Santa Maria, RS, Brasil. \\ ${ }^{4}$ Universidade Tecnológica Federal do Paraná, Dois Vizinhos, PR, Brasil. \\ *Autora para correspondência - flaniama@yahoo.com.br
}

\section{Resumo}

O estudo avaliou o comportamento ingestivo de bovinos terminados em confinamento com dieta de alto grão. Foram utilizados 45 animais do cruzamento das raças Charolês e Nelore, com peso e idade média inicial de $310 \mathrm{~kg}$ e 20 meses para os novilhos e $350 \mathrm{~kg}$ e 32 meses para as novilhas. Os animais foram distribuídos ao acaso nos tratamentos e bloqueados conforme a categoria. Foram utilizados 15 animais ( 8 novilhos e 7 novilhas) por tratamento, compostos por: Arroz (85\% de arroz); Aveia (85\% aveia) e Milho ( $85 \%$ milho), cada ingrediente acrescido de $15 \%$ de núcleo proteico, além de calcário calcítico e ureia. Os animais que receberam dieta à base de milho permaneceram mais tempo em ócio, menos tempo se alimentando e obtiveram maior número de refeições diárias, quando comparada aos outros tratamentos. Em relação ao tempo de ruminação, observa-se que os animais que consumiram dieta à base de aveia ruminaram mais tempo do que os demais que receberam os outros alimentos. $\mathrm{O}$ nível de FDN na dieta de bovinos confinados com dieta sem volumoso exerce influência sobre os tempos despendidos pelos animais em ruminação e ócio. No entanto, as dietas não alteram o tempo de alimentação.

Palavras-chave: Alto grão. Comportamento animal. Grão inteiro. Ócio. Ruminação.

\begin{abstract}
The study evaluated the ingestive behavior of bovines finished in feedlot with high grain diet. Fortyfive Charolais and Nelore crossbreds were used, with initial average weight and age of $310 \mathrm{~kg}$ and 20 months for the steers and $350 \mathrm{~kg}$ and 32 months for the heifers. The animals were randomly distributed in the treatments and blocked according the category. Fifteen animals ( 8 steers and 7 heifers) were used per treatment, composed by: Rice ( $85 \%$ of rice); Oat ( $85 \%$ oat) and Corn ( $85 \%$
\end{abstract}


corn), each ingredient plus $15 \%$ protein nucleus in addition to calcitic limestone and urea. The animals that received the diet based on corn remained more time in idle, less time on feeding and obtained a higher number of daily meals, when compared to the other treatments. Regarding the rumination time, it was observed that the animals that consumed the diet based on oat spent more time ruminating than the other treatments. The level of NDF in the diet of cattle confined with a non-roughage diet exerts an influence on the time spent by the animals in rumination and leisure, however, the diets do not alter feeding time.

Keywords: High grain. Animal behavior. Whole grain. Idleness. Rumination.

Recebido em: 29 de agosto de 2017.

Aceito em: 13 de setembro de 2019.

\section{Introdução}

A produção de bovinos de corte é uma das atividades mais representativas no Brasil, gerando renda para diversos setores, como produtores, frigoríficos, comércio, até chegar ao consumidor final, sem falar nos benefícios indiretos que a cadeia pode trazer. Cruz et al. ${ }^{(11)}$ comentam que o Brasil é um dos principais produtores de carne bovina do mundo e é considerado uma das únicas nações com condições de expansão de produção nessa atividade.

Existem diversos sistemas de produção bovina, e o confinamento, um desses sistemas, é uma alternativa interessante do ponto de vista produtivo. A terminação de bovinos de corte em regime de confinamento vem aumentando nos últimos anos, com o objetivo de reduzir a idade de abate dos animais e manter a produção de carne mais constante ${ }^{(17)}$.

Aliada ao sistema de terminação há também uma maior utilização de dietas com exclusiva participação de concentrados, denominadas alto grão. A escassez de volumosos de boa qualidade e preços baixos de alguns grãos incentivam o uso de dietas à base de concentrado para terminação de ruminantes ${ }^{(24)}$. Além disso, essas dietas proporcionam a redução de mão de obra de áreas destinadas a plantio de forragens, investimento em maquinários, itens que oneram os custos para a produção.

A escolha dos alimentos que compõem a dieta dos animais é um item importante a ser destacado. Com o aumento da produção e produtividade, utilização de grãos impróprios para o consumo humano e crises decorrentes no setor agrícola podem ocasionar baixos preços. Isso faz com que esses grãos sejam utilizados na alimentação dos animais, sendo fatores relevantes na escolha da dieta. Diante disso, várias alternativas de grãos podem ser utilizadas para a alimentação animal, como o milho, aveia branca e arroz com casca.

O Brasil terá uma produção estimada de 235,5 milhões de toneladas de grãos na safra 2018/19 (10), levando a um aumento da disponibilidade de cereais na indústria. Na cultura do milho (Zea mays), o Brasil encontra-se como o segundo maior produtor mundial, sendo esse grão um dos alimentos mais nutritivos utilizados na alimentação humana e animal. Outro cereal bastante cultivado principalmente no Rio Grande do Sul, que é o maior produtor nacional - é o arroz (Oriza sativa), que é um dos principais alimentos na nutrição humana. No entanto, para os ruminantes são mais utilizados seus subprodutos e não o grão inteiro com casca. Além desses grãos, a aveia branca (Avena sativa L.) 
tem sido uma alternativa na alimentação animal, embora bastante difundida na nutrição humana. É uma cultura regional favorecida pelas condições climáticas da região Sul e está em crescente expansão.

Em função do ingrediente, o consumo poderá ser afetado. Maia et al. ${ }^{(14)}$ observaram em dietas com alta densidade energética que o consumo pode ser limitado pela demanda energética e não pela limitação física, devido ao baixo teor de fibra em detergente neutro (FDN) em relação aos requerimentos do animal. No entanto, para Mendes et al. ${ }^{(15)}$, é importante utilizar em dietas com elevada participação de concentrado um teor mínimo de fibra, visto que estimula a mastigação e promove um ambiente ruminal adequado, não afetando o comportamento ingestivo e, consequentemente, o seu desempenho.

No entanto, são inexistentes os trabalhos científicos relacionados ao grão de arroz com casca na alimentação de bovinos. Os diversos alimentos passíveis de utilização na alimentação dos ruminantes causam diferenças no comportamento ingestivo dos animais, interferindo nas atividades de alimentação, ruminação e ócio, que, ao serem interpretadas juntamente a outros fatores, oferecem condições de avaliar se este alimento fornecido encontra-se adequado do ponto de vista nutricional (8).

Dessa maneira, Cattelam et al. ${ }^{(9)} \&$ Cirne et al. ${ }^{(10)}$ comentam que o estudo do comportamento animal é uma ferramenta que serve para ajustar o manejo alimentar e aprimorar o desempenho de bovinos de corte em confinamento. Assim, o objetivo do presente estudo é avaliar o comportamento ingestivo de bovinos terminados em confinamento com uso de dietas sem volumoso.

\section{Material e métodos}

O experimento foi conduzido no Laboratório de Bovinocultura de Corte do Departamento de Zootecnia da Universidade Federal de Santa Maria (UFSM). O local encontra-se na região fisiográfica denominada Depressão Central e apresenta como coordenadas $29^{\circ}$ e $43^{\prime}$ de Latitude Sul e $53^{\circ}$ e $42^{\prime}$ de Longitude Oeste. Este experimento foi conduzido de acordo com as normas éticas de bem-estar animal e foi aprovado pelo Comitê Interno de Ética em Experimentação Animal, da mesma instituição (Protocolo 118/2014). Foram utilizados 45 animais, sendo novilhos castrados e novilhas, produtos do cruzamento alternado rotativo das raças Charolês e Nelore do rebanho experimental do Departamento de Zootecnia da UFSM. Os animais apresentavam peso vivo e idade média inicial de $310 \mathrm{~kg} ; 350 \mathrm{~kg}$ e 20 meses; 30 meses de idade, respectivamente. Os animais foram balanceados e distribuídos de acordo com o peso vivo e escore de condição corporal e alocados em baias individuais de $10 \mathrm{~m}^{2}$, providas de comedouros individuais e bebedouros comuns a dois boxes, com piso de alvenaria, cobertas com telha de amianto.

Antecedendo o período experimental, os animais foram submetidos a um período de adaptação às instalações, manejo e às dietas experimentais, por um período de 28 dias. No início da adaptação os animais foram vermifugados com produto à base de sulfóxido de albendazol para controle de endoparasitas.

A dieta foi formulada de acordo com NRC ${ }^{(20)}$ a fim de atender os requerimentos nutricionais dos 
animais, objetivando ganho mínimo de 1,2 kg/animal/dia, estimando um consumo de matéria seca de $2,5 \mathrm{~kg} / 100 \mathrm{~kg}$ de peso vivo. Os tratamentos foram constituídos por diferentes tipos de grãos, não processados: grão de milho (Zea mays), grão de aveia branca (Avena sativa) e o grão de arroz com casca (Oryza sativa L.). A dieta foi constituída pelo grão inteiro (85\%), 15\% de núcleo concentrado comercial responsável por equilibrar a proteína e regular o $\mathrm{pH}$ ruminal, além de ureia, a fim de manter a dieta isonitrogenada, com proteína bruta de aproximadamente $14 \%$, e calcário calcítico para equilibrar a relação Ca:P da dieta, mantendo a proporção de 2:1.

A dieta ofertada aos animais foi "ad libitum", fornecida em duas refeições diárias ( $8 \mathrm{~h}$ e $14 \mathrm{~h})$, sendo as sobras pesadas e ajustadas diariamente de modo que oscilassem entre $5 \%$ e $8 \%$ do total de alimento ofertado. O grão foi distribuído no comedouro e, posteriormente, o núcleo, a ureia e o calcário calcítico, sendo realizada mistura manual para que os animais ingerissem de forma proporcional a dieta. Durante o período experimental, duas vezes por semana foram coletadas amostras representativas das dietas alimentares fornecidas aos animais, com o intuito de realizar posteriormente análise bromatológica da dieta. Além disso, periodicamente, amostras dos grãos também foram coletadas para serem analisadas (Tabela 1).

As amostras da dieta foram pré-secas em estufa com circulação de ar forçado a uma temperatura de $55{ }^{\circ} \mathrm{C}$, durante o período de 72 horas, para determinação do teor de matéria parcialmente seca. Após a pré-secagem, foram processadas em moinho tipo willey, com peneira com crivos de $1 \mathrm{~mm}$ de diâmetro e posteriormente armazenadas para análises bromatológicas, realizadas no Núcleo Integrado de Desenvolvimento em Análises Laboratoriais (NIDAL) da Universidade Federal de Santa Maria. No laboratório, foram determinados os teores de matéria seca (MS) em estufa a $105{ }^{\circ} \mathrm{C}$ por período de 16 horas. $\mathrm{O}$ conteúdo de cinzas foi determinado por calcinagem em mufla à temperatura de 550 ${ }^{\circ} \mathrm{C}$ durante 2 horas. As análises de matéria seca (MS), proteína bruta (PB) e extrato etéreo (EE) foram feitas segundo a AOAC ${ }^{(3)}$.

Tabela 1. Composição bromatológica dos ingredientes das dietas experimentais

\begin{tabular}{lcccccc}
\hline \multicolumn{1}{c}{ Teores, \% de MS } & Milho & Aveia branca & Arroz & Núcleo & Ureia & Calcário Calcítico \\
\hline Matéria Seca & 89,56 & 90,62 & 88,80 & 89,96 & 99,00 & 99,27 \\
Proteína Bruta & 9,34 & 12,25 & 7,84 & 32,21 & 281,00 & - \\
Extrato Etéreo & 3,83 & 4,48 & 1,55 & 3,95 & - & - \\
FDNc $^{1}$ & 13,84 & 31,77 & 21,67 & 29,27 & - & - \\
Lignina & 1,04 & 3,91 & 6,37 & 3,29 & - & - \\
Sílica & 0,19 & 0,47 & 2,37 & 1,59 & - & - \\
NDT $^{1}$ & 86,88 & 75,28 & 68,93 & 61,69 & - & - \\
$\mathrm{CNE}^{1}$ & 72,60 & 48,52 & 62,87 & 20,79 & - & - \\
\hline
\end{tabular}

${ }^{1} \mathrm{FDN}_{\mathrm{c}}$ : fibra em detergente neutro corrigido para cinzas; NDT: nutrientes digestíveis totais; CNE: carboidratos não estruturais.

Os teores de lignina em detergente ácido (LDA) e fibra insolúvel em detergente neutro corrigido para cinzas (FDNc) foram efetuados conforme Van Soest et al. ${ }^{(25)}$. O teor de nutrientes digestíveis totais (NDT) foi analisado conforme Weiss et al. ${ }^{(27)}$. Os valores de carboidratos não fibrosos (CNF) e carboidratos totais (CHT) foram calculados, em que $\mathrm{CHT}=100-(\% \mathrm{~PB}+\% \mathrm{EE}+\% \mathrm{CZ}), \mathrm{CNF}=$ CHT - FDN. A participação dos ingredientes e os valores da composição bromatológica das dietas experimentais são apresentados na Tabela 2. 
Tabela 2. Participação dos ingredientes (base na matéria seca) e composição bromatológica das dietas experimentais

\begin{tabular}{lccc}
\hline \multirow{2}{*}{ Ingredientes, g kg-1 de concentrado } & \multicolumn{3}{c}{ Dieta de alto grão } \\
\cline { 2 - 4 } & Milho & Aveia Branca & Arroz \\
\hline Milho & 835,0 & - & - \\
Aveia Branca & - & 840,0 & - \\
Arroz & - & - & 834,0 \\
Uréia & 5,0 & - & 9,0 \\
Calcário Calcítico & 10,0 & 10,0 & 7,0 \\
Núcleo Comercial & 150,0 & 150,0 & 150,0 \\
\hline & Composição bromatológica da dieta \\
\hline Matéria Seca, g/kg MN & 897,7 & 906,2 & 891,4 \\
Proteína Bruta, g/kg MS & 141,7 & 149,7 & 142,0 \\
Extrato Etéreo, g/kg MS & 37,8 & 43,5 & 18,9 \\
Fibra em Detergente Neutro, g/kg MS & 159,3 & 310,5 & 224,3 \\
Lignina, g/kg MS & 13,6 & 37,7 & 57,9 \\
Sílica, g/kg MS & 4,0 & 6,3 & 22,1 \\
Cinzas, g/kg MS & 52,0 & 76,4 & 99,2 \\
Nutrientes Digestíveis Totais, g/kg MS & 816,4 & 724,2 & 666,0 \\
Carboidratos Totais, g/kg MS & 768,4 & 729,2 & 739,9 \\
Carboidratos não Estruturais, g/kg MS & 636,1 & 438,5 & 553,8 \\
\hline
\end{tabular}

A coleta de dados do comportamento ocorreu ao longo dos períodos de confinamento, totalizando quatro observações diárias de 24 horas cada. A primeira avaliação comportamental ocorreu aos 28 dias, após os animais já estarem adaptados às dietas e instalações. As variáveis comportamentais estudadas consistiram no registro das atividades de tempo de consumo de alimento, ócio e ruminação, verificadas a cada 5 minutos.

Os dados do comportamento ingestivo foram interpretados conforme Burger et al. ${ }^{(6)}$, obtidos pelas seguintes equações: ERMS $=\mathrm{CMS} / \mathrm{TRT}, \quad \mathrm{ERFDN}=\mathrm{CFDN} / \mathrm{TRT}, \quad \mathrm{NBOLO}=\mathrm{TRT} / \mathrm{TMB}$, TMT=TA+TRT, NMMD=NMMB*NBOLO, TOT=TOE+TOD e TRT=TRE+TRD; em que: ERMS = eficiência de ruminação de matéria seca, g MS/h; CMS = consumo de matéria seca, g MS/dia; ERFDN = eficiência de ruminação da fibra em detergente neutro, g FDN/h; CFDN = consumo de fibra em detergente neutro, g FDN/dia; TMT = tempo de mastigação total, h/dia; TA = tempo de alimentação total, $\mathrm{h} / \mathrm{dia}$; NBOLO = número de bolos mastigados por dia, $\mathrm{n} / \mathrm{dia}$; TMB $=$ tempo de mastigação merícica por bolo ruminal, seg/bolo; NMMD = número de mastigadas merícicas por dia enquanto ruminava, $\mathrm{n}$ /dia; TOT = tempo de ócio total, $\mathrm{h} / \mathrm{dia} ; \mathrm{TOE}=$ tempo de ócio em pé, h/dia; TOD = tempo de ócio deitado, h/dia; TRT = tempo de ruminação total, h/dia; TRE = tempo de ruminação em pé, h/dia; TRD= tempo de ruminação deitado (para direita ou esquerda); $\mathrm{NMB}=$ número de mastigadas por bolo ruminal; $\mathrm{TMMB}=$ tempo despendido na mastigação merícica por bolo ruminal, seg/bolo, sendo essa variável quantificada com o auxílio de um cronômetro digital.

Também foi quantificado o consumo de matéria seca, expresso em peso absoluto, sendo que os animais do tratamento milho tiveram o consumo de 7,38 kg/dia, aveia branca, $8,23 \mathrm{~kg} / \mathrm{dia}$ e os animais do tratamento arroz consumiram $6,96 \mathrm{~kg} /$ dia. Para os cálculos das eficiências de ruminação da matéria seca (ERMS) e da fibra em detergente neutro (ERFDN) foram utilizados o consumo de matéria seca e o consumo de fibra em detergente neutro dos dias em que foram realizados os comportamentos. 
O delineamento experimental utilizado foi de blocos ao acaso, no qual a categoria animal foi o critério para bloqueamento, com três tratamentos e quinze repetições, sendo o animal a unidade experimental. Os dados foram comparados pelo procedimento PROC MIXED com avaliações repetidas no tempo. Para cada variável analisada foram testadas diferentes estruturas de covariância, sendo utilizada na respectiva variável a estrutura que apresentou menor valor de "Akaike's Information Criterion" (AIC). Quando detectada diferença significativa entre as médias, elas foram comparadas pelo teste de diferença mínima significativa (DMS), através do teste “t” de Student, a $\alpha=0,05$ de probabilidade. O procedimento estatístico utilizado foi o SAS (Statistical Analysis System, versão 9.2).

O modelo matemático para as todas variáveis foi o seguinte:

$$
\mathrm{Y}_{\mathrm{ij}}=\mu+\mathrm{T}_{\mathrm{i}}+\beta_{\mathrm{j}}+\left(\mathrm{T}_{\mathrm{i}} * \beta_{\mathrm{j}}\right)+\varepsilon_{\mathrm{ij}}, \text { em que: }
$$

$\mathrm{Y}_{\mathrm{ij}}=$ variáveis dependentes; $\mu=$ média de todas as observações; $\mathrm{T}_{\mathrm{i}}=\mathrm{o}$ efeito do i-ésimo tratamento; $\beta_{\mathrm{j}}=$ efeito da j-ésima categoria animal; $\left(\mathrm{T}_{\mathrm{i}} * \beta_{\mathrm{j}}\right)=\mathrm{o}$ efeito da interação do i-ésimo tratamento com a j-ésima categoria (erro a) e $\varepsilon_{\mathrm{ij}}=$ erro aleatório residual.

\section{Resultados e discussão}

Não foi observada interação entre os fatores estudados no presente trabalho. Para o tempo de alimentação de bovinos terminados em confinamento sem volumosos (Tabela 3) não foi observado diferença significativa $(\mathrm{P}>0,05)$. A ruminação total foi menor $(\mathrm{P} \leq 0,05)$ para os animais do tratamento à base de milho, diferindo dos animais do tratamento arroz, que, por sua vez, foi menor que aqueles do tratamento aveia. Esse resultado pode ser explicado pelo menor teor de FDN e maior teor de carboidratos não estruturais presente na dieta experimental do tratamento milho em comparação à dieta aveia branca ou arroz (Tabela 2). Para Van Soest ${ }^{(26)}$, o tempo de ruminação está diretamente relacionado à natureza da dieta, sendo que alimentos com maior proporção de FDN precisam sofrer mais mastigações e consequentemente mais ruminações que alimentos com menor teor de FDN.

Outro ponto a ser levado em consideração é o teor da fibra fisicamente efetiva dessas dietas, sendo que o grão de aveia apresenta maior efetividade, fazendo com que os animais ruminem por mais tempo. A fibra fisicamente efetiva é a fração do alimento que estimula a atividade de mastigação, que por sua vez estimula maior salivação, que é tamponante natural ${ }^{(16)}$ para neutralizar os ácidos produzidos durante a fermentação ruminal, evitando que o $\mathrm{pH}$ diminua e ocorra algum distúrbio metabólico, como a acidose. De acordo com o autor acima ${ }^{(16)}$ citado, para calcular a fibra fisicamente efetiva é feita a separação vertical em uma peneira de $1,18 \mathrm{~mm}$, na qual é usada a porcentagem de FDN que fica retida nessa peneira.

Dessa maneira, o mesmo autor relata que, quando a dieta contiver partículas maiores que 1,18 mm, elas possuem alta resistência à passagem através do rúmen no qual irão formar materiais flutuantes, promovendo contato com a parede do rúmen e, consequentemente, estimulando a ruminação para reduzir essas partículas. Esse fato foi observado no presente estudo, sendo que os animais que receberam aveia apresentaram em sua dieta maior teor de FDN (Tabela 2) e, consequentemente, maior fibra fisicamente efetiva, que, por sua vez, apresentou maior tempo de ruminação (Tabela 3). Por isso, em dietas de alto grão, os grãos devem ser fornecidos inteiros, pois assim não reduzem a 
efetividade física da FDN, diminuindo possíveis problemas ruminais em função da dieta. Para Mertens ${ }^{(16)}$, o tamanho da partícula deve ser de no mínimo 1,2 mm para que ocorra a contração ruminal e por fim a ruminação. Em trabalho realizado por Bernardes ${ }^{(5)}$, avaliando diferentes grãos separadamente (milho, aveia branca, aveia preta e arroz), também foi observado menor tempo de ruminação para os ovinos que receberam grão de milho em sua dieta e, consequentemente, maior tempo em ócio, mesmo comportamento observado no presente estudo.

Tabela 3. Médias, erros padrão (EP) e probabilidade para a distribuição das atividades comportamentais de bovinos terminados em confinamento com dieta de alto grão

\begin{tabular}{|c|c|c|c|c|c|}
\hline \multirow{2}{*}{ Variável, h/dia } & \multicolumn{3}{|c|}{ Tratamentos } & \multirow[b]{2}{*}{$\mathbf{E P}^{1}$} & \multirow[b]{2}{*}{ Probabilidade } \\
\hline & Milho & Aveia & Arroz & & \\
\hline Tempo de ingestão de água & 0,13 & 0,09 & 0,11 & 0,01 & 0,0679 \\
\hline Tempo de alimentação & 2,22 & 1,97 & 2,18 & 0,12 & 0,1132 \\
\hline Ruminação total & $1,90^{\mathrm{c}}$ & $6,38^{\mathrm{a}}$ & $3,23^{\mathrm{b}}$ & 0,20 & 0,0001 \\
\hline Ruminação deitado total & $1,86^{\mathrm{c}}$ & $5,68^{\mathrm{a}}$ & $3,03^{\mathrm{b}}$ & 0,19 & 0,0001 \\
\hline Ruminação em pé total & $0,04^{\mathrm{c}}$ & $0,70^{\mathrm{a}}$ & $0,20^{\mathrm{b}}$ & 0,06 & 0,0001 \\
\hline Ócio total & $19,87^{\mathrm{a}}$ & $15,64^{\mathrm{c}}$ & $18,58^{b}$ & 0,23 & 0,0001 \\
\hline Ócio deitado total & $13,07^{\mathrm{a}}$ & $10,05^{\mathrm{c}}$ & $11,90^{\mathrm{b}}$ & 0,36 & 0,0001 \\
\hline Ócio em pé total & $6,78^{a}$ & $5,59^{c}$ & $6,68^{\mathrm{b}}$ & 0,35 & 0,0013 \\
\hline
\end{tabular}

a,b,c - médias com diferenças significativas $(\mathrm{P} \leq 0,05)$ possuem letras diferentes

${ }^{1} \mathrm{EP}$ - erro-padrão

Os animais que receberam dieta à base de aveia mantiveram-se mais tempo deitados em ruminação, seguidos dos animais do tratamento com arroz, que, por sua vez, permaneceram por tempo maior que os animais alimentados com milho. De acordo com Oliveira et al. ${ }^{(21)}$ e Pinto et al. ${ }^{(22)}$, ruminar deitado é a posição em que os animais não se sentem ameaçados, indicando condições de tranquilidade, conforto e bem-estar, embora em condições ambientais desfavoráveis (ventos, chuvas) possam permanecer em pé ou caminhar lentamente. Para a variável ruminação total em pé (Tabela 3), observa-se que os animais alimentados com aveia permaneceram maior tempo nessa posição, seguidos dos alimentados com arroz, que por sua vez ficaram mais tempo em pé do que os alimentados com o milho. Fato que já foi explicado anteriormente, essa diferença deve-se ao maior teor de FDN da dieta com aveia branca (Tabela 2), o que proporcionou maior tempo de ruminação aos animais daquele tratamento.

Os animais do tratamento grão de milho apresentaram maior tempo em ócio total (Tabela 3), comparados aos animais do tratamento grão de arroz, que por sua vez permaneceram maior tempo em ócio que os animais alimentados com dieta à base de grão de aveia. $\mathrm{O}$ ócio representa o tempo em que o animal não está ingerindo alimento e nem ruminando, podendo estar em pé ou deitado, mas geralmente os animais permanecem maior tempo em ócio deitados no período noturno ${ }^{(2)}$. Quando se avalia o tempo de ócio de um animal, essa variável se torna importante em animais de produção, ou seja, o animal que está em ócio terá seus gastos em energia reduzidos ${ }^{(19)}$. Esses resultados observados no presente estudo são consequência do menor tempo em ruminação total para os animais da dieta milho, seguido da dieta arroz e por último da dieta que continha aveia. Além disso, o teor de fibra em detergente neutro (FDN) na dieta dos animais que receberam milho (Tabela 2) é menor quando comparado aos demais tratamentos, fato que demanda menor ruminação. Para Barreto et al. (4),à medida que ocorre a redução da fibra em detergente neutro da dieta e ao mesmo tempo a elevação do 
nível de carboidratos não estruturais, os animais podem reduzir os períodos de alimentação e ruminação e consequentemente aumentar o seu tempo de ócio total.

Os valores referentes ao número e tempo de mastigadas por bolo (Tabela 4) de bovinos terminados em confinamento com dieta de alto grão apresentaram resultados significativos $(\mathrm{P} \leq 0,05)$ para os grãos testados. Os animais submetidos ao tratamento aveia apresentaram maior número de vezes de mastigadas por bolo e também permaneceram maior tempo mastigando o bolo ruminal, quando comparado aos animais do tratamento milho e arroz, que não diferiram entre si, resultado atribuído principalmente à composição química da dieta (Tabela 2), que, consequentemente, demandou maior tempo despendido para a atividade de ruminação (Tabela 3) dos animais que ingeriram aveia, traduzidas por um maior número e tempo de mastigadas por bolo.

Os animais do tratamento aveia apresentaram maior número de bolos regurgitados por dia (Tabela 4), diferindo dos animais do tratamento arroz, e esses, por sua vez, menor do que do tratamento milho. Isso está relacionado às atividades de ruminações e ao tempo para ruminar cada bolo, em consequência do teor de FDN das dietas, sendo que os animais do tratamento aveia apresentaram em sua composição maior porcentagem de FDN, fazendo com que os animais ruminassem mais tempo cada bolo regurgitado e tivessem maior número de bolos regurgitados por dia. Além disso, o número de bolos ruminados por dia depende do tempo de ruminação e também está relacionado ao tempo gasto para ruminar cada bolo (Tabela 4), que foi superior para os animais alimentados com grão de aveia. Conforme a composição bromatológica da dieta (Tabela 2) observa-se que o tratamento com grão de milho apresenta maior quantidade de carboidratos não fibrosos, promovendo rápida degradação dos carboidratos no rúmen, causando diminuição no número de bolos ruminados.

Tabela 4. Número e tempo de mastigadas e bolos de bovinos terminados em confinamento com dieta de alto grão

\begin{tabular}{|c|c|c|c|c|c|}
\hline \multirow{2}{*}{ Variável } & \multicolumn{3}{|c|}{ Tratamentos } & \multirow[b]{2}{*}{$\mathrm{EP}^{1}$} & \multirow[b]{2}{*}{ Probabilidade } \\
\hline & Milho & Aveia & Arroz & & \\
\hline Número de mastigas/bolo & $60,04^{b}$ & $75,26^{\mathrm{a}}$ & $54,79^{\mathrm{b}}$ & 2,90 & 0,0001 \\
\hline Tempo de mastigadas/bolo, segundos & $63,50^{\mathrm{b}}$ & $80,45^{\mathrm{a}}$ & $62,60^{\mathrm{b}}$ & 3,01 & 0,0001 \\
\hline Número de bolos/dia & $115,02^{\mathrm{c}}$ & $307,00^{\mathrm{a}}$ & $194,81^{b}$ & 15,92 & 0,0001 \\
\hline Número de mastigadas merícicas ruminativas/min.* & $56,4^{\mathrm{a}}$ & $56,6^{\mathrm{a}}$ & $52,7^{\mathrm{b}}$ & 0,96 & 0,0001 \\
\hline Número de mastigadas merícicas ruminativas/dia & $6.804^{\mathrm{c}}$ & $21.749^{\mathrm{a}}$ & $10.326^{\mathrm{b}}$ & 743,42 & 0,0001 \\
\hline Tempo de mastigação total, horas & $4,12^{\mathrm{c}}$ & $8,35^{\mathrm{a}}$ & $5,41^{\mathrm{b}}$ & 0,23 & 0,0001 \\
\hline
\end{tabular}

$\mathrm{a}, \mathrm{b}, \mathrm{c}$ - médias com diferenças significativas $(\mathrm{P} \leq 0,05)$ possuem letras diferentes.

${ }^{1} \mathrm{EP}$ - erro-padrão

*Minutos

O número de mastigadas merícicas por minuto (Tabela 4) foi similar para os animais do tratamento milho e aveia, no entanto diferiram do tratamento arroz $(\mathrm{P} \leq 0,05)$. Valores verificados no presente trabalho são semelhantes aos encontrados por Missio et al. ${ }^{(18)}$, que verificaram 53,19 mastigadas para o nível de concentrado 79\%. Para o número de mastigadas merícicas diárias durante a ruminação (Tabela 4), observa-se que os animais do tratamento aveia foram superiores aos animais do tratamento arroz, que foi superior aos do tratamento milho. Isso pode estar relacionado ao aumento do número de bolos ruminados por dia (Tabela 4), que também foi superior para o tratamento aveia, pois, conforme Tabela 2, a dieta com grão de aveia apresentou maior porcentagem de FDN, aumentando o número de mastigadas merícicas ruminativas por dia e o tempo de ruminação. No presente trabalho, 
o tratamento aveia obteve 21.749 mastigadas por dia. Já quando comparado ao trabalho realizado por Callegaro ${ }^{(7)}$ observou-se diferença entre os grãos testados para o número de mastigadas ruminativas por dia (18.922 mastigadas) para o tratamento grão de aveia, valor inferior ao presente estudo.

O tempo despendido na mastigação total (Tabela 4) foi inferior para os animais que receberam na sua dieta milho, quando comparado ao fornecimento da dieta com arroz, que, por sua vez, foi menor ao dos animais alimentados com aveia. Pode-se observar (Tabela 2) que a dieta composta por aveia apresenta maior teor de FDN. Por causa disso, os animais alimentados com esta dieta permaneceram mais tempo mastigando e, consequentemente, ruminando, sendo que o tempo gasto com a ruminação é proporcional ao teor de parede celular dos alimentos, contendo maiores teores de FDN em sua composição. Os animais alimentados com grão de milho permaneceram menor tempo na atividade de mastigação total em função do menor teor de FDN.

Foi observada diferença entre os tratamentos para as eficiências de ruminação da matéria seca (ERMS) e da fibra em detergente neutro (ERFDN) (Tabela 5). Os animais alimentados com milho obtiveram melhor resultado quando comparados aos que consumiram arroz, que por sua vez foram superiores aos alimentados com aveia. Esses resultados são reflexos do menor teor de FDN da dieta, pois, para Missio et al. ${ }^{(18)}$, dietas com menor FDN podem proporcionar maior eficiência de ruminação da MS. Já quando as dietas apresentam maiores níveis de FDN (Tabela 2), sua eficiência diminuiu, fato observado neste estudo, no qual os animais alimentados com aveia foram menos eficientes que os demais tratamentos, devido à proporção fibrosa da dieta.

Em relação à eficiência de ruminação da fibra em detergente neutro (ERFDN) (Tabela 5), observa-se que os animais do tratamento milho foram mais eficientes quando comparados aos alimentados com arroz e aveia. Esse comportamento é em função da dieta apresentar menor proporção de FDN, que por sua vez reflete em maior taxa de passagem do alimento pelo trato gastrintestinal dos animais.

Tabela 5. Eficiências de ruminação da matéria seca (MS) e da fibra em detergente neutro (FDN) de bovinos terminados em confinamento com dieta de alto grão

\begin{tabular}{|c|c|c|}
\hline \multirow{2}{*}{ Variáveis } & \multirow{2}{*}{\multicolumn{2}{|c|}{$\frac{\text { Tratamentos }}{\text { MilhoAveiaArroz EP }{ }^{1} \text { Probabilidade }}$}} \\
\hline & & \\
\hline Eficiência de Ruminação na Matéria seca, g MS/h & $4430^{\mathrm{a}} 1441^{\mathrm{c}} 2891^{\mathrm{b}} 0,23$ & 0,0001 \\
\hline ERFDN*, g FDN/h & $803^{\mathrm{a}} \quad 490^{\mathrm{c}} \quad 746^{\mathrm{b}} 0,12$ & 0,0001 \\
\hline
\end{tabular}

a,b,c - médias com diferenças significativas $(\mathrm{P} \leq 0,05)$ possuem letras diferentes; ${ }^{1} \mathrm{EP}$ - erro-padrão.

*Eficiência de Ruminação na Fibra em detergente neutro.

A ERFDN está diretamente relacionada à digestibilidade da fibra e, consequentemente, ao desempenho animal, sendo que em dietas com teores mais elevados de fibra os microrganismos precisam ser muito eficientes para degradá-la e transformá-la em ganho de peso. Diante disso, é de extrema importância a avaliação da eficiência, pois quanto melhor essa variável, melhor será o desempenho animal. Em trabalho realizado por Bernardes ${ }^{(5)}$, que avaliou o comportamento ingestivo de ovinos alimentados com diferentes dietas de alto grão (milho, aveia branca, aveia preta e arroz), esse autor obteve o mesmo resultado para a ERFDN, sendo que os animais alimentados com grão de milho foram mais eficientes que nos demais tratamentos.

A distribuição da alimentação, em porcentagem, durante 24 horas de avaliação comportamental de bovinos terminados com dieta de alto grão, está apresentada na Figura 1. Torna-se evidente que o pico de alimentação está concentrado durante o fornecimento da ração diária. Após a segunda 
alimentação, nos horários entre as $16 \mathrm{~h}$ e $18 \mathrm{~h}$, ocorreu novamente um terceiro pico de alimentação. Possivelmente isso se explica pelo fato da última refeição ter sido fornecida às $14 \mathrm{~h}$. Dessa forma, a concentração de tempo consumindo alimento ficou entre os períodos das $8 \mathrm{~h}$ às $18 \mathrm{~h}$.

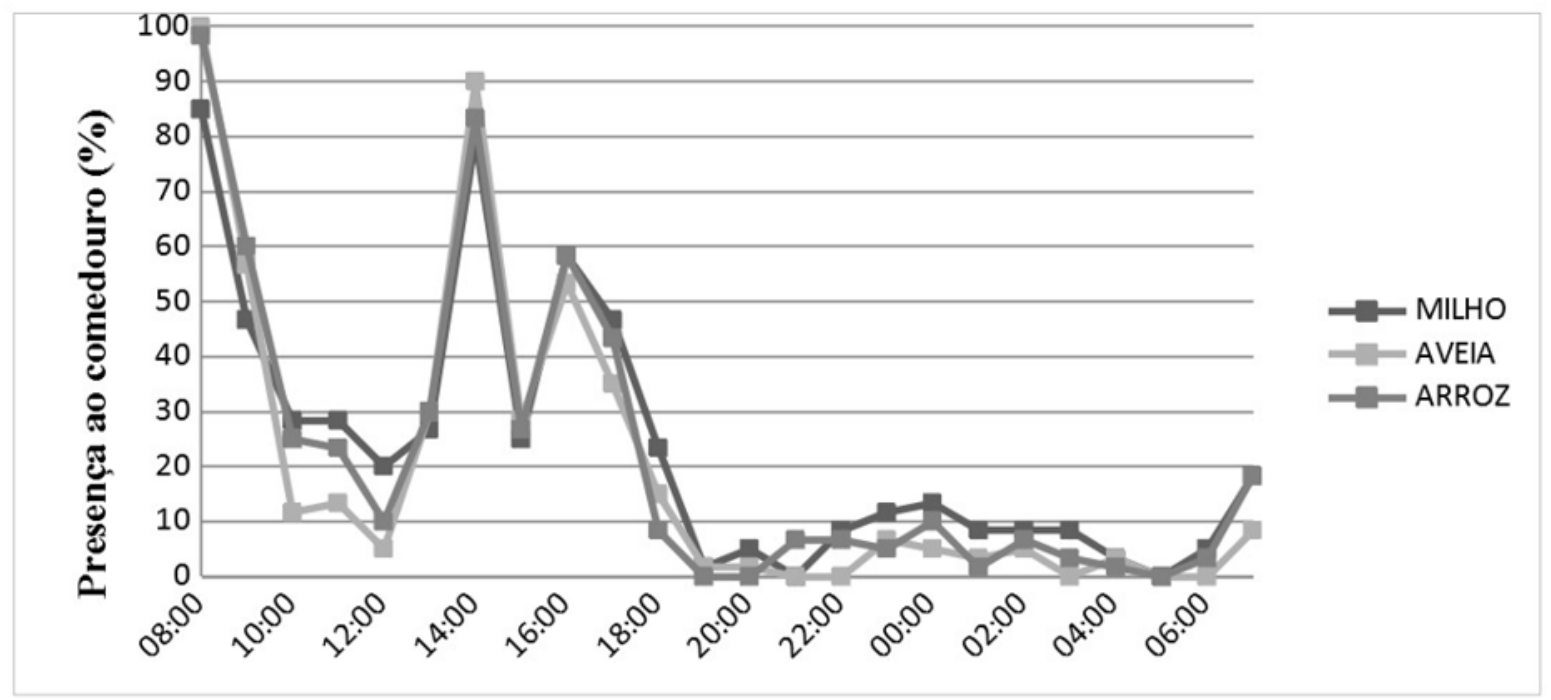

Figura 1 - Presença ao comedouro dos bovinos terminados com dieta de alto grão (\%).

Em trabalho realizado por Freitas et al. ${ }^{(13)}$ foi verificado maior presença dos animais ao comedouro no horário próximo ao fornecimento da alimentação. Já Dulphy e Faverdin ${ }^{(12)}$ observaram que, além das principais refeições, quando se é fornecido o alimento, existe um número de refeições secundárias, fato que ocorreu neste estudo, como citado anteriormente.

\section{Conclusões}

Ao se utilizar o grão de aveia branca na alimentação animal, eles despenderam mais tempo na atividade de mastigação e ruminação em comparação aos animais alimentados com milho ou arroz, proporcionando melhor eficiência de alimentação e ruminação do alimento.

Animais alimentados com grão de milho apresentam maior tempo de ócio, sendo um aspecto importante na produção, ou seja, o animal não apresenta gasto energético e com isso torna-se um fator considerável para o maior ganho de peso, além de terem feito maior número de refeições diárias.

A dieta composta por grão de arroz não influencia no tempo de alimentação dos animais.

Nota dos autores: $O$ presente artigo relata parte da pesquisa realizada para a tese de doutorado em Zootecnia da primeira autora pela Universidade Federal de Santa Maria, RS.

\section{Referências}

1.Almeida GLP, Pandorfi H, Barbosa SBP, Pereira DF, Guiselini C, Almeida GAP, Comportamento, produção e qualidade do leitede vacas Holandês-Gir com climatização no curral. Revista Brasileira deEngenharia Agrícola e Ambiental, 2013; 17(8):892-899. http://www.scielo.br/scielo.php?pid=S1415$\underline{43662013000800014 \& \text { script }=\text { sci_abstract } \& \ln g=\mathrm{pt}}$ 
2. Argenta FM, Brondani IL, Alves Filho DC, Nornberg JL, Segabinazi LR, Restle J, Weise MS, Borchate D, Rodrigues LS, Moura AF. Comportamento ingestivo de novilhos alimentados com silagem de capim papuã (Urochloa plantaginea) x silagem de sorgo (Sorghum bicolor (L.) Moench) Revista Acadêmica, Ciências $\begin{array}{llll}\text { Agrárias } & \text { e } & \text { Ambientais. 2013; } & \text { 11(3):243-253. }\end{array}$ http://www2.pucpr.br/reol/pb/index.php/academica?dd1=12662\&dd99=view\&dd98=pb

3. Association of Official Analytical Chemistry. Official methods of analysis. $16^{\text {th }}, 3$. Ed. Aoac International, Gaithersburg, MD. 1997.

4. Barreto LMG, Medeiros AN, Batista AMV, Furtado DA, Araújo GGL, Lisboa ACC, Paulo JLA, Souza CMS. Comportamento ingestivo de caprinos das raças Moxotó e Canindé em confinamento recebendo dois níveis de energia na dieta. Revista Brasileira de Zootecnia. 2011; 40(4):834-842. http://www.scielo.br/scielo.php?script=sci_abstract\&pid=S151635982011000400018\&lng=pt\&nrm=iso\&tln $\mathrm{g}=\mathrm{pt}$

5. Bernardes GMC. Uso de dietas de alto grão na terminação de cordeiros em confinamento. 86 p. Dissertação - Mestrado (Produção Animal). Centro de Ciências Agrárias, Universidade Federal de Santa Maria - RS, 2014. http://repositorio.ufsm.br/handle/1/10853

6. Burger PJ, Pereira JC, Queiroz AC, Silva JFC, Valadares Filho SC, Cecon PR, Casali ADP. Comportamento ingestivo em bezerros holandeses alimentados com dietas contendo diferentes níveis de concentrado. Revista $\begin{array}{llll}\text { Brasileira } & \text { Zeotecnia. } & 2000 ; & 29(1): 236-242 .\end{array}$ http://www.scielo.br/scielo.php?script=sci_arttext\&pid=S1516-35982000000100031

7. Callegaro, A.M. Dietas de alto grão no comportamento, desempenho e qualidade da carne de novilhos confinados. 2014. 207p. Tese (Doutorado). Centro de Ciências Agrárias, Universidade Federal de Santa Maria - RS. http://bdtd.ibict.br/vufind/Record/UFSM_4f7e7bf4e0b02cd7496942c9582a165a

8. Carvalho S, Dias FD, Pires CC, Brutti DD, Lopes JF, Santos D, Barcelos RD, Macari S, Wommer TPE, Griebler L. Comportamento ingestivo de cordeiros texel e ideal alimentados com casca de soja. Archivos de Zootecnia. 2014;63(241):55-64.

http://www.uco.es/ucopress/az/index.php/az/article/view/563

9. Cattelam J, Brondani IL, Alves Filho DC, Silva JHS, Segabinazzi LR, Pizzuti LAD, Mayer AR, Wyzykowski A, Pereira LB, Machado DS. Padrões comportamentais de novilhos confinados com diferentes espaços individuais. Current Agricultural Science and Technology. 2013; 19:82-95. file:///C:/Users/Profissional/Downloads/3247-6887-1-PB\%20(2).pdf

10. CONAB. Companhia Nacional de Desenvolvimento. $7^{\circ}$ Levantamento de Grãos-Abril de 2019. https://www.conab.gov.br/info-agro/safras/graos

11.Cirne LGA, Sobrinho AGS, Santana VT, Silva FU, Lima NLL, Oliveira EA, Carvalho GGP, Zeola NMBL, Takahashi R. Comportamento ingestivo de cordeiros alimentados com dietas contendo feno de amoreira. Semina: Ciências Agrárias. 2014;35(2):1051-1060. file:///C:/Users/Profissional/Downloads/13419-75942-1PB.pdf

12. Cruz R S, Alexandrino E, Missio RL,Restle J, Melo JC, Paula Neto JJ, Neiva JM, Mendes Filho GO, Souza Júnior A, Duarte TD, Rezende JM, Silva AAM. Desempenho bioeconômico de tourinhos alimentados com níveis de concentrado e farelo do mesocarpo de babaçu. Semina: Ciências Agrárias, Londrina. 2014; 35(4):2159-2174. http://www.redalyc.org/articulo.oa?id=445744142037

13. Dulphy JP,Faverdin PL. Ingestion alimentaire chez les ruminants: modalités et phénomènes associés. Reprodution, Nutrition Développement. 1987; 27(1B):129-155.

https://rnd.edpsciences.org/articles/rnd/abs/1987/02/RND_0181-1916_1987_27_1B_ART0002/RND_0181-

Cienc. anim. bras., Goiânia, v.20, 1-13, e-49508, 2019 


\section{1B ART0002.html}

14. Freitas LS, Silva JHS, Segabinazzi LR, DA Silva VS, Alves Filho DC, Brondani IL. Substituição da silagem de milho por silagem de girassol na dieta de novilhos em confinamento: comportamento ingestivo. Revista Brasileira de Zootecnia. 2010; 39(1):225-232.

http://www.scielo.br/scielo.php?pid=S1516-35982010000100030\&script=sci_abstract\&tlng=pt

15. Maia ISG, Pereira ES, Pinto AP, Mizubuti IY, Ribeiro ELA, Carneiro MSS, Campo ACN, Gadelha CRF, Júnior JNR. Consumo, avaliação do modelo small ruminant nutrition system e predição da composição corporal de cordeiros Santa Inês alimentados com rações contendo diferentes níveis de energia. Semina: Ciências Agrárias. 2014;35(4):2579-2596. Suplemento. file:///C:/Users/Profissional/Downloads/1428588301-1-PB\%20(1).pdf

16. Mendes CQ, Tiruno VF, Susin I, Pires AV, Morais JB, Gentil RS. Comportamento ingestivo de cordeiros e digestibilidade dos nutrientes de dietas contendo alta proporção de concentrado e diferentes fontes de fibra em detergente neutro. Revista Brasileira de Zootecnia. 2010; 39(3):594-600. http://www.scielo.br/scielo.php?script=sci arttext\&pid=S1516-35982010000300019

17. Mertens DR. Creating a system for meeting the fiber requirements of dairy cows. Journal of Dairy Science. 1997; 80(7):1463-1481. http://citeseerx.ist.psu.edu/viewdoc/download?doi=10.1.1.168.3307\&rep=rep1\&type=pdf

18. Miotto FRC, Neiva JNM, Restle J, Falcão AJS, Castro KJ, Maciel RP. Comportamento ingestivo de tourinhos alimentados com dietas contendo níveis de gérmen de milho integral. Ciência animal brasileira. 2014; 15(1):45-54. https://www.revistas.ufg.br/vet/article/view/24627/16218

19. Missio RL, Brondani IL, Alves Filho DC, Silveira MF, Freitas LS, Restle J. Comportamento ingestivo de tourinhos terminados em confinamento, alimentados com diferentes níveis de concentrado na dieta. Revista Brasileira de Zootecnia. 2010; 39(7):1571-1578. http://www.scielo.br/scielo.php?pid=S1516$\underline{35982010000700025 \& \text { script }=\text { sci_abstract } \& \text { tlng }=p t}$

20. Mousquer CJ, Fernandes GA, Hoffmann WJRCA, Simioni TA, Fernandes FFD. Comportamento ingestivo de ovinos confinados com silagens. Revista Brasileira de Higiene e Sanidade Animal. 2013; 7(2):301-322. http://www.higieneanimal.ufc.br/seer/index.php/higieneanimal/article/view/87

21. McAllister TA, Hristov AN, Beauchemin KA. Enzymes in ruminant diets. In: Bedford MR, Partridge GG. Enzymes in farm animal nutrition. Oxon: Cab International, 2001. Cap. 11, p.273-298 http://beefextension.com/files/Proceedings\%20final.pdf

22. National Research Council - NRC. Nutrient requeriments of beef cattle.7 ed. Washington, D.C.: National Academy Press, 2001. 242p.

23. Oliveira PA, Marques JÁ, Barbosa LP, Oliveira GJC, Pedreira TM, Silva LL. Aspectos metodológicos do comportamento ingestivo de vacas lactantes em pastejo de Brachiaria decumbens. Revista Brasileira de Saúde e Produção Animal. 2011; 12(1):166-175. http://revistas.ufba.br/index.php/rbspa/article/viewArticle/1889

24. Pinto AP, Marques JÁ, Abrahão JJS, Nascimento WG, Costa MAT, Lugão SMB. Comportamento e eficiência ingestiva de tourinhos mestiços confinados com três dietas diferentes. Archivos de Zootecnia. 2010;59(227):427-434. http://scielo.isciii.es/scielo.php?script=sci arttext\&pid=S0004-05922010000300010

25. Sistema IBGE de Recuperação Automática - SIDRA. Estatísticas. 2014. Disponível em: http://www.sidra.ibge.gov.br. Acesso em: 29 de dezembro de 2014.

26. Sormunen-Cristian R. Effect of barley and oats on feed intake, live weight gain and some carcass characteristics of fattening lambs. Small Ruminant Research.2013; 109(1):22-27. http://www.sciencedirect.com/science/article/pii/S0921448812002684 
27. Van Soest PJ, Robertson JB, Lewis BA. Symposium: carboydrate metodology, metabolism, and nutritional implications in dairy cattle. Journal Dairy Science. 1991; 74(10):3583-3597. http://agris.fao.org/agrissearch/search.do?recordID $=$ XL2012003810

28. VanSoest PJ. Nutritional ecology of the ruminant.2.ed. Ithaca: Cornell Univ. Press, 1994. 476 p. http://www.cornellpress.cornell.edu/book/?GCOI=80140100037050

29. Weiss WP, Conrad HR, Pierre NR. A theoretically-based model for predicting total digestible nutrient values of forages and concentrates. Animal FeedScience and Technology. 1992; 39(1-2): p.95-110. http://www.sciencedirect.com/science/article/pii/0377840192900344 